\title{
HLA-DRB1 typing of Vogt-Koyanagi-Harada's disease by PCR-RFLP and the strong association with $\mathrm{DRB} 1 \star 0405$ and $\mathrm{DRB} 1 \star 0410$
}

\author{
Yumiko Shindo, Hidetoshi Inoko, Takuji Yamamoto, Shigeaki Ohno
}

\begin{abstract}
Vogt-Koyanagi-Harada's (VKH) disease is reported to be closely associated with the HLA class II antigen, HLA-DR4. Serologically defined DR4 is further divided into 11 alleles by molecular HLA genotyping. However, no study of HLA-DNA typing of VKH patients has been reported. To clarify molecular genetic mechanism underlying the susceptibility/resistance to VKH disease, HLA-DNA typing of DR antigens (DRB1 genotyping) by the polymerase chain reaction-restriction fragment length polymorphism (PCR-RFLP) method was performed. It was found that DRB1*0405 showed a significant association with VKH disease compared with the healthy controls (corrected $p$ value $<1 \times 10^{-5}$ ) and that all the patients had DRB1*0405 and/or DRB1*0410. The specific amino acid residue shared only by these two alleles is Ser at position 57 which is located in the antigen binding groove and may influence the immunological function as an antigen-presenting molecule, suggesting that Ser at position 57 plays an important role in the susceptibility to VKH disease, although the possibility that the involvement of the HLA-DQ molecule, DQ4, in strong linkage disequilibrium with DRB1*0405 and DRB1*0410, cannot be excluded.
\end{abstract}

(Brf Ophthalmol 1994; 78: 223-226)

The HLA class II region in the major histocompability complex (MHC) on human chromosome 6 encodes the heterodimeric ( $\alpha$ and $\beta$ chains) glycoproteins expressed on the surface of antigen-presenting cells in the immune system. The $\mathrm{T}$ cell receptor interacts with a complex formed by the antigenic peptide fragment bound by the HLA molecule on the antigen-presenting cells. On the basis of $x$ ray crystallographic analysis of the HLA class I antigen, HLA-A2, the outermost domains of each class II chain are predicted to fold together to form a groove and cleft, and so appear to function by trapping the antigenic peptide fragment into a groove for the presentation to antigenic-restricted $T$ cells in the initiation of immune response. The genetic polymorphism of class II molecules is known to be clustered into the discrete regions of the $\beta$ chains termed allelic hypervariable regions (AHVR). ${ }^{12}$ AHVR regulate the variability of immune responsiveness through the antigen recognition by MHC restricted $T$ cells. Thus the polymorphic amino acid residues in AHVR of the HLA class II molecule have been suggested to have an important role in determining the susceptibility/resistance to many autoimmune diseases, ${ }^{3}$ such as insulin dependent diabetes mellitus, ${ }^{45}$ rheumatoid arthritis, ${ }^{67}$ and myasthenia gravis.

Vogt-Koyanagi-Harada's (VKH) disease is a bilateral panuveitis of inflammatory disorders in multiple organs such as meningitis, hearing loss, tinnitus, and vitiligo. ${ }^{8-12}$ We previously reported that VKH disease was closely associated with HLA-DR4 and DR53 by serological HLA typing in Japanese VKH patients. ${ }^{1314}$ This association was confirmed in Han Chinese VKH patients. ${ }^{15}$ PCR (polymerase chain reaction) based DNA typing has revolutionised the precise definition of HLA class II allelic polymorphisms reflecting the amino acid residues in AHVR. ${ }^{16-19}$ For example, serologically defined HLA-DR4 is further divided into 11 alleles which can be distinguished only by PCR genotyping. However, there has been no investigation of precise HLA-DR genotyping in VKH disease. In this study, we examined the polymorphic distribution of DRB1 alleles including 11 HLA-DR4 associated alleles among Japanese $\mathrm{VKH}$ patients in order to manifest specific amino acid(s) of the DRB1 gene responsible for determination of the predisposition to VKH disease.

\section{Materials and method}

\section{SUBJECTS}

Forty unrelated Japanese VKH patients were diagnosed, treated, and followed in the uveitis survey clinic of the Yokohama City University Hospital. Seventy controls were randomly selected from healthy unrelated Japanese.

SEROLOGICAL TYPING

The VKH patients and the healthy controls were subjected to serological HLA typing for HLA class I and class II antigens, using the standard NIH complement microlymphocytotoxicity technique. ${ }^{20}$

\section{DNA TYPING BY PCR-RFLP}

Genomic DNAs from 40 patients and 70 healthy controls were isolated by phenol extraction of sodium dodecyl sulphate lysed and proteinase $\mathrm{K}$ treated cells. They were amplified by the PCR procedure with the Taq DNA polymerase and typed by the PCR-restriction fragment length protein (RFLP) method as described previously. ${ }^{21}$ Out of 70 healthy controls, 28 had DRB1*04 (DR4) (Table 2). For detailed analysis 
of DRB1 ${ }^{\star} 04$ suballelic genotyping, $27 \mathrm{DRB} 1^{\star} 04$ positive healthy individuals were further collected as controls (Table 3 ) (55 DRB $1{ }^{\star} 04$ positive healthy controls in total).

Briefly, for the PCR selective amplification, seven group specific 5' primers for the DRB1 genes (reflecting the first AHVR of the polymorphic exon 2 domain) were used along with a common $3^{\prime}$ primer as described elsewhere..$^{162}$ The reaction mixture was subjected to 30 cycles of 1 minute at $96-97^{\circ} \mathrm{C}$ for denaturation, 1 minute at $55-62^{\circ} \mathrm{C}$ for annealing, and 2 minutes at $72^{\circ} \mathrm{C}$ for extension of the annealed primers by automated PCR thermal sequencer (Iwaki Glass Inc, Tokyo). After amplification, aliquots of the reaction mixture were digested with the allelespecific restriction endonucleases for 3 hours after addition of appropriate reaction buffer. Samples of the restriction enzyme cleaved amplified DNAs were subjected to electrophoresis in a $12 \%$ polyacrylamide gel in a minigel apparatus (Mupid-2, Cosmo Bio Co Ltd, Tokyo). Cleavage or non-cleavage of amplified fragments was detected by staining with ethidium bromide. Discrimination of genotypes of DRB1 genes was determined on the basis of RFLP band patterns thus generated. ${ }^{21}$ Nomenclature of DRB1 alleles was according to the factors of the HLA system, as suggested by the WHO nomenclature committee..$^{18}$

\section{STATISTICAL ANALYSIS}

The $\chi^{2}$ method with the continuity correction and Fisher's exact test were used for data analysis. The $p$ values obtained were multiplied by the number of comparisons made to correct for the number of alleles $\left(\mathrm{pc}=\right.$ corrected $\mathrm{p}$ value) ${ }^{22}$ Relative risk (RR) was calculated according to Wolf's method with the Holdane's correction.

\section{Results}

SEROLOGICAL HLA TYPING

The frequency of the HLA antigens, relative risk (RR), and corrected $\mathrm{p}$ value ( $\mathrm{pc}$ ) were calculated in 40 Japanese $\mathrm{VKH}$ patients and in 70 unrelated Japanese controls (Table 1).

HLA-DR4, DR53, and DQ4 were significantly increased in the VKH patients compared with the healthy controls $(\mathrm{DR} 4: \mathrm{RR}=120 \cdot 8$, $\mathrm{pc}<1 \times 10^{-5}, \quad \mathrm{DR} 53: \mathrm{RR}=48 \cdot 2, \quad \mathrm{pc}<1 \times 10^{-3}$, $\left.\mathrm{DQ} 4: \mathrm{RR}=11 \cdot 6, \mathrm{pc}<1 \times 10^{-5}\right)$. It was noteworthy that DR4 and DR53 were present in $100 \%$ of the VKH patients examined.

On the other hand, HLA-DR6 and DR52 were negatively associated with the VKH patients compared with the healthy controls by p value, but these differences were not statistically significant after correction of the $p$ values (DR6:RR $=0 \cdot 1, \mathrm{p}<5 \times 10^{-2}, \mathrm{DR} 52: \mathrm{RR}=0 \cdot 27$, $\left.\mathrm{p}<5 \times 10^{-2}\right)$.

HLA-DNA TYPING

HLA-DRB1 genotyping was carried out by the PCR-RFLP method. The results of the DRB1 allelic frequencies in the VKH patients and the healthy controls are shown in Table 2 . All the patients had DRB1*04 (DR4) as expected from the results of serological typing. DRB $1 \star 0405$ was significantly increased in the VKH patients when compared with the healthy controls $(R R=$ $\left.43 \cdot 7, \mathrm{pc}<1 \times 10^{-5}\right)$. The frequencies of all the other DRB1 alleles were not statistically different between the VKH patients and the healthy controls.

Among 70 healthy individuals here examined, 28 carried $\mathrm{DRB}^{\star}{ }^{*} 04$ (DR4). To analyse the suballelic distribution of the DRB1*04 (DR4) molecule precisely in the $\mathrm{VKH}$ patients, an additional $27 \mathrm{DRB} 1^{\star} 04$ positive healthy individuals were enrolled (in total, $55 \mathrm{DRB}{ }^{\star} 04$ positive healthy controls), typed by PCR-RFLP (Table 3). DRB1*0405 was again significantly increased in the VKH patients compared with the $\mathrm{DRB} 1{ }^{\star} 04$ positive healthy controls $(\mathrm{RR}=$ $\left.11 \cdot 1, \mathrm{pc}<5 \times 10^{-3}\right)$. It must also be noted that all the VKH patients who did not have DRB1 0405 possessed DRB1*0410.

\section{Discussion}

Our data have confirmed a strong association of the serologically defined HLA-DR4 and DR53 in the Japanese VKH patients. However, HLADR53 itself was unlikely to confer susceptibility to VKH disease because no increase of DR9 or DR7, which is also known to be tightly linked to HLA-DR53, could be observed in the VKH

Table 1 HLA class II antigen frequencies of VogtKoyanagi-Harada's disease

\begin{tabular}{lcccc}
\hline $\begin{array}{l}\text { HLA } \\
\text { antigen }\end{array}$ & $\begin{array}{l}\text { Controls } \\
(n=70)\end{array}$ & $\begin{array}{l}\text { Patients } \\
(n=40)\end{array}$ & $\begin{array}{l}\text { Relative } \\
\text { risk }\end{array}$ & $p$ c Value \\
\hline DR1 & $4(5 \cdot 7 \%)$ & $4(10 \cdot 0 \%)$ & & \\
DR2 & $8(11 \cdot 4 \%)$ & $5(12 \cdot 5 \%)$ & & \\
DR4 & $28(40 \cdot 0 \%)$ & $40(100 \cdot 0 \%)$ & $120 \cdot 8$ & $<1 \times 10^{-5}$ \\
DR5 & $9(12 \cdot 8 \%)$ & $6(15 \cdot 0 \%)$ & & \\
DR6 & $19(27 \cdot 1 \%)$ & $2(5 \cdot 0 \%)$ & & \\
DR8 & $8(11 \cdot 4 \%)$ & $1(2 \cdot 5 \%)$ & & \\
DR9 & $17(24 \cdot 3 \%)$ & $10(25 \cdot 0 \%)$ & & \\
DR10 & $4(5 \cdot 7 \%)$ & 0 & & \\
DR52 & $41(58 \cdot 6 \%)$ & $11(27 \cdot 5 \%)$ & & $<1 \times 10^{-3}$ \\
DR53 & $44(62 \cdot 9 \%)$ & $40(100 \cdot 0 \%)$ & $48 \cdot 2$ & \\
DQ1 & $20(28 \cdot 6 \%)$ & $16(40 \cdot 0 \%)$ & & \\
DQ3 & $42(60 \cdot 0 \%)$ & $22(55 \cdot 0 \%)$ & 11.6 & $<1 \times 10^{-5}$ \\
DQ4 & $13(18 \cdot 6 \%)$ & $29(72 \cdot 5 \%)$ & $11 \cdot 6$ & \\
\hline
\end{tabular}

Level of significance (corrected $\mathrm{p}$ value $=\mathrm{pc}$ ) was set to be less than 0.05 .

Table 2 HLA-DRB1 frequencies of Vogt-KoyanagiHarada's disease

\begin{tabular}{|c|c|c|c|c|}
\hline$D B R I$ & $\begin{array}{l}\text { Controls } \\
(n=70)\end{array}$ & $\begin{array}{l}\text { Patients } \\
(n=40)\end{array}$ & $\begin{array}{l}\text { Relative } \\
\text { risk }\end{array}$ & pc Value \\
\hline 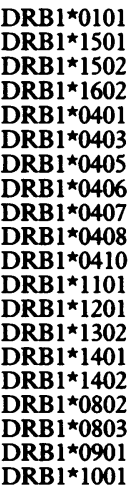 & $\begin{array}{c}8(11 \cdot 4 \%) \\
11(15 \cdot 7 \%) \\
17(24 \cdot 3 \%) \\
0 \\
3(4 \cdot 3 \%) \\
6(8 \cdot 6 \%) \\
18(25 \cdot 7 \%) \\
7(10 \cdot 0 \%) \\
2(2 \cdot 9 \%) \\
1(1 \cdot 4 \%) \\
0 \\
2(2 \cdot 9 \%) \\
8(11 \cdot 4 \%) \\
11(15 \cdot 7 \%) \\
7(10 \cdot 0 \%) \\
3(4 \cdot 3 \%) \\
1(1 \cdot 4 \%) \\
9(12 \cdot 9 \%) \\
15(21 \cdot 4 \%) \\
1(1 \cdot 4 \%)\end{array}$ & $\begin{array}{l}5(12 \cdot 5 \%) \\
3(7 \cdot 5 \%) \\
3(7 \cdot 5 \%) \\
1(2 \cdot 5 \%) \\
0 \\
0 \\
38(95 \cdot 0 \%) \\
3(7 \cdot 5 \%) \\
1(2 \cdot 5 \%) \\
1(2 \cdot 5 \%) \\
3(7 \cdot 5 \%) \\
1(2 \cdot 5 \%) \\
1(2 \cdot 5 \%) \\
1(2 \cdot 5 \%) \\
1(2 \cdot 5 \%) \\
1(2 \cdot 5 \%) \\
1(2 \cdot 5 \%) \\
0 \\
9(22 \cdot 5 \%) \\
0\end{array}$ & $43 \cdot 7$ & $<1 \times 10^{-5}$ \\
\hline
\end{tabular}

Level of significance (corrected p value: $p c$ ) was set to be less than 0.05 . 
Table $3 \quad D R B 1{ }^{\star} 04$ suballelic frequencies of the DR4 positive patients with Vogt-Koyanagi-Harada's disease and healthy controls

\begin{tabular}{|c|c|c|c|c|}
\hline$D B R I$ & $\begin{array}{l}\text { DR4 positive } \\
\text { controls } \\
(n=55)\end{array}$ & $\begin{array}{l}\text { Patients } \\
(n=40)\end{array}$ & $\begin{array}{l}\text { Relative } \\
\text { risk }\end{array}$ & $p c$ Value \\
\hline $\begin{array}{l}\text { DRB } 1^{\star} 0401 \\
\text { DRB } 1^{\star} 0403 \\
\text { DRB } 1^{\star} 0405 \\
\text { DRB } 1^{\star} 0406 \\
\text { DRB } 1^{\star} 0407 \\
\text { DRB } 1^{\star} 0408 \\
\text { DRB } 1^{\star} 0410\end{array}$ & $\begin{array}{c}3(5 \cdot 5 \%) \\
9(16 \cdot 4 \%) \\
32(58 \cdot 2 \%) \\
7(12 \cdot 7 \%) \\
2(3 \cdot 6 \%) \\
1(1 \cdot 8 \%) \\
0\end{array}$ & $\begin{array}{l}0 \\
0 \\
38(95 \cdot 0 \%) \\
3(7 \cdot 5 \%) \\
1(2 \cdot 5 \%) \\
1(2 \cdot 5 \%) \\
3(7 \cdot 5 \%)\end{array}$ & $11 \cdot 1$ & $<5 \times 10^{-3}$ \\
\hline
\end{tabular}

Level of significance (corrected p value: $p c$ ) was set to be less than 0.05 .

patients. Therefore, HLA-DR4 was considered to play a decisive role in the development of VKH disease. Recently, the PCR based DNA typing techniques, such as PCR-SSO (sequence specific oligonucleotide) and PCR-RFLP, can split HLA antigens into multiple alleles at the nucleotide level, especially HLA class II molecules. The serologically defined HLA-DR antigen can be divided into many alleles reflecting polymorphisms of the amino acid sequence in the AHVR of the $\beta$ chain. For example, $\mathrm{DRB1}{ }^{\star} 04$ (HLA-DR genes) can be divided into 11 alleles (DRB1*0401-DRB1*0411). We adopted the PCR-RFLP method as the first molecular analysis for HLA polymorphisms for the genetic susceptibility to VKH disease in this study, because it is a simple, rapid, sensitive, inexpensive, and practical technique as described previously. ${ }^{1621}$ The most important outcome in this DRB1 genotyping was that DRB $1^{\star} 0405$ was significantly increased when compared with the healthy controls $(R R=43 \cdot 7$, pc $<1 \times 10^{-5}$ ) (Table 2).

Numaga et $a l^{23}$ also investigated the relation between VKH disease and HLA-DR4 at the molecular level by the PCR-SSO method. However, the number of SSO probes they used was limited and could not allow full DRB $1{ }^{\star} 04$ genotyping. They selected three probes including the nucleotide sequence of DRB $1 \star 0405$. Probe 1 was common in all the DR4 genes, probe 2 represented the amino acid sequence specific for DRB ${ }^{\star} 0404,0405,0408$, and probe 3 corresponded to the third AHVR of DRB1 ${ }^{\star 0404}$, 0405, 0408, 0101, and 1402. So these three probes cannot cover all the genetic variations of $11 \mathrm{DRB}{ }^{\star}$ 04 alleles, although they found that all but one patients (19 of 20 ) had a specific sequence encoding amino acids 70 and 71 of the DR $\beta$ chain detected by probe 3 . In our studies, there was no significant difference in the frequencies of DRB1 $1^{\star} 0101$ and $D R B 1^{\star} 1402$ in the VKH patients when compared with 70 healthy controls (Table 2). Consequently, there was not enough of their data to discuss which DRB1*04 allele could be attributed to susceptibility to VKH disease.

We performed the complete DRB1 genotyping by the PCR-RFLP method and found that all the patients had DRB1*04 alleles and that $\mathrm{DRB1}{ }^{\star 0405}$ was significantly associated with VKH disease (Table 2). To confirm the significant association with DRB ${ }^{\star} 0405$ in $\mathrm{VKH}$ patients, we compared the DRB1*04 suballelic frequencies of $40 \mathrm{VKH}$ patients with those of 55
DRB1*04 (DR4) positive healthy controls (Table 3$). \mathrm{DRB}{ }^{\star}{ }^{0} 405$ was again significantly increased when compared with the DR4 positive healthy controls. In addition, all the VKH patients who did not have $\mathrm{DRB} 1 * 0405$ possessed $D R B 1{ }^{\star} 0410$, suggesting that the susceptibility to VKH disease was determined by the presence of the shared functional epitope common to $D R B 1{ }^{\star} 0405$ and DRB1*0410. The published amino acid sequences of the polymorphic $\beta$ domains of the DRB1 genes show that the amino acid specific for both DRB1*0405 and 0410 is serine (Ser, a neutral amino acid) at position 57 instead of aspartic acid (Asp, an acidic amino acid) as in many other DRB1 alleles (Table 4). DRB1*0409 and DRB1*0411, also having Ser at position 57 , are quite rare in Japanese people and so cannot be expected to show an increase in the Japanese VKH patients. The model of the HLA class II molecular conformation ${ }^{24} 25$ was predicted on the basis of the three dimensional crystal structure of the HLA class I molecule, HLA-A2. ${ }^{26}$ In this model, the amino $\left(\mathrm{NH}_{2}\right)$ terminal sequences of the $\alpha 1$ and $\beta 1$ domains are predicted to form a floor of four $\beta$ strands which is topped by two $\alpha$ helixes, one formed by the carboxy $(\mathrm{COOH})$ terminal portion of the $\alpha 1$ domain and the other by the $\mathrm{COOH}$ terminal sequence of the $\beta 1$ domain. Some residues are predicted to point into the antigen-binding site and some others, projecting upwards, are likely to be involved in direct interaction with the $T$ cell receptor. A non-conservative amino acid change at any of these positions could affect both peptide binding and $T$ cell recognition. The amino acid sequence differences among 11 DR4 associated alleles are confined to the $\mathrm{COOH}$ terminal portion of the $\beta 1$ domain, primarily within the third AHVR of the DRB1 gene. ${ }^{17}{ }^{27}$ Hence, the polymorphic residues in this region are believed to be critical in both $T$ cell recognition and antigenic peptide binding. Ser instead of Asp at position 57, a non-conservative amino acid change seen in all the VKH patients, being positioned at one end of the $\alpha$ helix, is predicted to point towards the peptide binding cleft and to interact with the processed peptide fragment, indicating that Ser at position 57 may play a crucial role in the susceptibility to VKH disease.

Table 4 Comparison of the amino acid sequences in the hypervariable regions of the $D R B 1$ chains among $D R B 1^{\star} 0101, D R B 1^{\star} 04$, and $D R B 1^{\star} 1402$ in relation to Vogt-Koyanagi-Harada's disease susceptibility

\begin{tabular}{|c|c|c|c|c|c|c|c|c|}
\hline & & & 57 & 67 & 70 & 71 & 74 & 86 \\
\hline \multirow{12}{*}{$\begin{array}{l}\text { DR1 } \\
\text { DR4 }\end{array}$} & Dwl & DRB $1 * 0101$ & D & $\mathbf{L}$ & $\mathbf{Q}$ & $\mathbf{R}$ & A & G \\
\hline & Dv & 0401 & - & $\overline{-}$ & - & $\mathbf{K}$ & - & $=$ \\
\hline & Dw10 & DRB $1 * 0402$ & - & I & D & $\mathbf{E}$ & - & $\mathrm{V}$ \\
\hline & Dw13a & DRB $1 * 0403$ & - & - & - & - & $\mathbf{E}$ & \\
\hline & Dw14a & DRB $1 * 0404$ & - & - & - & - & - & t \\
\hline & Dv & $\star 0405$ & $\mathbf{S}$ & - & - & - & - & - \\
\hline & DwKT2 & DRB $1 * 0406$ & - & - & - & - & $\mathbf{E}$ & 1 \\
\hline & Dw13b & DRB $1 * 0407$ & - & - & - & - & $\mathbf{E}$ & - \\
\hline & Dw 14b & $\mathrm{DRB} 1 \star 0408$ & - & - & - & - & - & \\
\hline & ? & DRB $1 * 04$ & $\mathbf{S}$ & - & - & $\mathbf{K}$ & - & \\
\hline & ; & DRB $1 * 0410$ & $\mathbf{S}$ & - & - & - & - & $V$ \\
\hline & & DF & $\mathbf{S}$ & - & - & - & $\mathbf{E}$ & $v$ \\
\hline DR6 & Dw16 & DRB $1 * 14$ & - & - & - & - & - & \\
\hline
\end{tabular}

Amino acid sequences were translated from the nucleotide sequences and given by the standard one letter code. A dash indicates identification with the DRB1*0101 (DR1 Dw1) sequence. DRB ${ }^{\star} 0405,0409,0410$, and 0411 carry Ser (neutral amino acid) at position 57 . 
We demonstrated that DRB1*0405 and DRB $1{ }^{\star} 0410$ were closely associated with VKH disease. The distribution of DR4 associated alleles is known to be different among races, so predicting that the incidence of VKH disease might be less prevalent in white populations where $\mathrm{DRB1}{ }^{\star} 0405$ and $\mathrm{DRB} 1{ }^{\star} 0410$ are rare. ${ }^{28}$ In fact, VKH disease occurs frequently in orientals, especially Japanese, American Indians and Hispanic people, but is rare in white people, revealing that the susceptible locus of $\mathrm{VKH}$ disease may be strongly associated with some ethnic specific allele(s).

Strong linkage disequilibrium exists between HLA-DR and DQ molecules and differs among races. ${ }^{29}$ At present, the involvement of the HLA-DQ molecule cannot be excluded because $\mathrm{DRB1}{ }^{\star} 0405$, the most significant increased allele in the VKH patients, is in a close linkage disequilibrium with $\mathrm{DQB1}^{\star 04}$ (DQ4) in Japanese. In fact, serologically defined DQ4 is also significantly increased in $\mathrm{VKH}$ patients when compared with healthy controls (Table 1 ). To address this issue, HLA-DQ genotyping of Japanese VKH patients is now being performed in our laboratory.

In this study, it was suggested that Ser at position 57 of DRB1 gene was closely associated with VKH disease and further HLA-DQ genotyping will be important to understand molecular mechanism for the susceptibility to VKH disease. In order to understand the molecular relation between the immunogenetic mechanism and pathogenesis of $\mathrm{VKH}$ disease, analysis of the peptide sequence derived from foreign or self antigens responsible for the development of the disease, for its presentation by the HLA DRB1*0405 or DRB1*0410 molecule, and also for the effects of these particular HLA class II alleles on T cell receptors during $T$ cell ontogeny will be necessary.

1 Mengel-Gaw L, McDevitt HO. Genetics and expression of mouse Ia antigens. Ann Rev Immunol 1985; 3: 367-96.

2 Bell JI, Denny DD, Foster L, Belt T, Todd JA, McDevitt HO. Allelic variation in the DR subregion of the human major histocompatibility complex. Proc Natl Acad Sci USA 1987; 84: 6234-8.

3 Neopom GT. Immunogenetics of HLA-associated diseases. Concepts Immunopathol 1988; 5: 80-105.

4 Todd JA, Bell JA, McDevitt HO. HLA-DQ $\beta$ gene contributes to susceptibility and resistance to insulin dependent diabetes mellitus. Nature 1987; 329: 599-604.

5 Martell M, Marcadet A, Moine A, Boitard AM, Deshamps I, Dausset $\mathrm{J}$, et al. Heterogeneity of HLA genetic factors in
IDDM susceptibility. Immunogenetics 1990; 31: 233-40.

6 Ollier W, Carthy D, Cutbush S, Okoye R, Awad J, Fielder A, et al. HLA-DR4 Dw types in rheumatoid arthritis. Tissue Antigens 1988; 33: 30-7

Watanabe Y, Tokunaga K, Matsuki K, Takeuchi F, Matsuta $\mathrm{K}$, Maeda $\mathrm{H}$, et al. Putative amino acid sequence of HLADRB chain contributing to rheumatoid arthritis susceptibility. F Exp Med 1989; 169: 2263-8.

8 Vogt A. Fruhezeitiges Ergaven der Zilien und Bemerkungen uber den sogennanten plotzlichen Entritt dieser

Koyanagi Y. Dysakuisis, Alopecia und Poliosis 45: 228-42. Uveitis nichit traumatischen Ursprungs. Klin Monastbl Augenheilkd 1929; 82: 194-211.

10 Harada Y, Beitrag zur Klinischen Keutuis von michteitriger Choroiditis (choroiditis diffusa acta). Acta Ophthalmol fpn 1926; 30: 356-78.

11 Sugiura S. Vogt-Koyanagi-Harada disease. fpn Ophthalmol 1978; 22: 9-35.

12 Synder DA, Tessler HH. Vogt-Koyanagi-Harada syndrome. Am $\mathcal{F}$ Ophthalmol 1980; 90: 69-75.

13 Ohno S. Immunological aspects of Behçet's and VogtKoyanagi-Harada's diseases. Trans Ophthalmol Soc UK 1981; 101: 335-41.

14 Ohno S. Vogt-Koyanagi-Harada's disease. In: Sarri KM, ed. Uveitis update. Amsterdam: Elsevier, 1984: 401-5.

15 Zhao M, Jiang Y, Abrahams W. Association of HLA antigens with Vogt-Koyanagi-Harada syndrome in a Han Chinese with Vogt-Koyanagi-Harada syndrome in a Han

population. Arch Ophthalmol 1991; 109: $368-70$.
16 Inoko H. PCR-RFLP method holds great promise for complete HLA class II genotyping. Tissue Antigens 1990; 36: 88-92.

17 Petesdorf EW, Smith AG, Mickelson EM, Martin PJ, Hansen JA. Ten HLA-DR4 alleles defined by sequence polymorphisms within the DRB1 first domain. Immunogenetics 1990 33: 267-75.

18 Bodmer JG, Marsh SGE, Albert ED, Bodmer WF, Dupont B, Erlich HA, et al. Nomenclature for factors of the HLA system, 1990. Hum Immunol 1991; 31: 186-94.

19 Marsh SGE, Bodmer JG. HLA class II nucleotide sequences, 1991. Tissue Antigens 1991; 37: 181-9.

20 Terasaki PI, Mac Cell. Microdroplet assay of human serum Terasaki PI, Mac Cell. Microdroplet assay
cytotoxins. Nature 1964; 204: 998-1000.

21 Ota M, Seki T, Fukushima H, Tsuji K, Inoko H. HLA DRB1 genotyping by modified PCR-RFLP method combined with group-specific primers. Tissue Antigens 1992; 39: 187-202.

22 Bachelor JR, MacMicheal AJ. Progress in understanding HLA and disease associations. Br Med Bull 1987; 43: 156 83.

23 Numaga J, Matsuki K, Taking $K$, Juji T, Mochizuki $M$. Analysis of human leukocyte antigen HLA-DR amino acid sequence in Vogt-Koyanagi-Harada syndrome. Invest Ophthalmol Vis Sci 1991; 32: 1958-61.

24 Bjorkman PJ, Saper MA, Samraoui B, Bennett WS Bjorkman PJ, Saper MA, Samraoui B, Bennett WS,
Strominger JL, Wiley DC. The foreign antigenic binding Strominger $\mathrm{JL}$, Wiley $\mathrm{DC}$. The foreign antigenic binding
site and $T$ cell recognition regions of class I histosite and $T$ cell recognition regions of class
compatibility antigens. Nature $1987 ; 329: 512-8$.

25 Brown JH, Jardetzky T, Saper MA, Samraoui B, Bjorkman PJ, Wiley DC. A hypothetical model of the foreign antigen binding site of class II histocompatibility molecules. Nature 1988; 332: 845-50.

26 Bjorkman PJ, Saper MA, Samraoui B, Bennett WS Strominger JL, Wiley DC. Structure of the human class I histocompatibility antigen, HLA-A2. Nature 1987; 329: 506-12.

27 Lanchbury JSS, Hall MA, Welsh KI, Panayi GS. Sequence analysis of HLA-DR4BI subtypes: additional first domain variability is detected by oligonucleotide hybridization and variability is detected by oligonucleotide hybridization and

28 Ohno S, Char DH, Kimura SJ, O'Conner GR. VogtKoyanagi-Harada syndrome. Am $f$ Ophthalmol 1977; 83. 735-40.

29 Korman AJ, Bass JM, Spies T, Sorrentino R, Okada K, Strominger JL. Genetic complexity and expression of human class II histocompatibility antigens. Immunol Rev 1985; 85: 45-86. 